\title{
Predilection and growth performance of FUNAAB-Alpha chicken under different compact fluorescent light colours
}

${ }^{1}$ Adeleye, O. O., ${ }^{2}$ Baldeh, Y., ${ }^{1}$ Egbeyale, L. T., ${ }^{1}$ Akinremi, F. M., ${ }^{2}$ Oso, O. M., ${ }^{1}$ Fajimi, S. O., ${ }^{1}$ Olorunsogbon, B. F., ${ }^{3}$ Jegede, A. V., ${ }^{1}$ Abatan, M., ${ }^{4}$ Adebambo A. O. and ${ }^{4}$ Adebambo O. A.

${ }^{I}$ Department of Animal Production and Health, Federal University of Agriculture, Abeokuta.

${ }^{2}$ Center of Excellence in Agricultural Development and Sustainable Environment (CEADESE), Federal University of Agriculture, Abeokuta. ${ }^{3}$ Department of Animal Nutrition, Federal University of Agriculture, Abeokuta.

${ }^{4}$ Department of Animal Breeding and Genetics, Federal University of Agriculture, Abeokuta.

Abstract Corresponding author: gbengamcf@yahoo.co.uk; +2348132146857

The predilections of FUNAAB-Alpha chicken for Compact Fluorescent Light colours (CFL) and their effect on growth performance were evaluated. Three hundred and ninety six (396) FUNAAB-Alpha chickens were randomly divided into three treatments, each contained a coloured CFL light bulb of $45 \mathrm{~W}$ and equal light intensity: T1 (Yellow CFL), T2 (Blue CFL), T3 (White CFL). Artificial lighting was provided for 8 hours from 8pm-4am. Dark to light predilection test was carried out at $2^{\text {nd }}$ week of age. Birds under yellow light had enhanced $(P<0.05)$ frequency of feeding behaviour (3.6) compared to those under blue (1.1) and white (0.7) light respectively. Moreover, birds that preferred yellow light exhibited higher frequency $(P<0.05)$ of drinking behaviour (0.6) compared to those that preferred other lights. Growth performance result revealed that birds reared under blue light had enhanced average feed intake (77.4) compared to birds reared under white (69.2) and yellow (70.0) light colours. The result of the growth performance revealed that birds under blue light had improved feed intake. Yellow light is recommended for rearing of FUNAAB Alpha chickens at the early stage.

Keywords: Behaviour, growth performance, predilection test, FUNAAB Alpha chicken.

\section{Introduction}

Lighting is a basic part of the environment that can impact the wellbeing, productivity, and welfare of confined broilers (Olanrewaju et al., 2006). Light seems to be the most imperative stimuli that the domestic fowl, gallus domesticus, gets from the physical environment (Perry and Lewis, 1993). Natural lighting (sunlight) is significantly different from the artificial lighting utilized in poultry houses (Angélica 2013). This is because sun light wavelength is within the ranges of 350 and $700 \mathrm{~nm}$, while artificial light sources give a smaller range of wavelengths (Prescott, 1999).Many physiological processes in poultry are influenced by light, thus response of birds differ according to the type of wavelengths they are exposed. Light colour has been reported to affect skeletal muscle growth with higher muscle weights being observed in birds reared under blue or green lights (Halevy, 2003). It was also reported by Rozenboim et al. (2004) that green light stimulates growth at an early stage of poultry birds life while blue light has calming effect and stimulates reproduction in poultry birds. Predilection is an important tool in animal welfare research which gives insight into what the animals want in a given moment. However, due to their social nature, broiler birds can 


\section{Predilection and growth performance of FUNAAB-Alpha chicken}

sometimes influence each other's choice, hence, it is more appropriate to test their predilections in a group than testing them individually. It also worth noting that the previous experience of an animal will probably affect its predilection since in poultry; the familiar resource is often preferred initially, although this predilection is bound to change with time and experience of other resources. Therefore it is pertinent to ensure that all the resources are equally familiar to the broilers before enabling them to choose between them (Davis et al., 1999). The fact that the fowl has predilections for different light environments has been shown by researchers such as (Widowski et al., 1992). In recent years, most predilection tests have been used to observe the relationship between lighting and behaviour in poultry and the predilection of poultry has also been assessed for different light intensities, light sources, light colours and flickering frequencies (Widowski and Duncan, 1996; Prayitno and Philips, 1997; Davis et al.1999;). Research conducted by Prayitno et al. (1997) showed that poultry birds are likely to prefer other colours even when reared under a different colour during their early stages of growth.

Adeleye et al. (2018) carried out a research on the effects of incandescent light (ICD) and Compact Fluorescent Light (CFL) on growth performance and preference of broiler chickens, and discovered that birds raised under ICD (Yellow) had increased feed intake and higher growth rate, while CFL (White) reduced pecking behaviour among broiler birds. The obtained results were attributed to colour rather than bulb type, this therefore, makes it necessary to conduct a similar experiment using different colours of the same bulb type. This is basically the motive for this research on predilection of FUNAAB Alpha chickens for compact fluorescent light colours and their effects on growth performance.

\section{Materials and methods Experimental site}

The experiment was carried out at the poultry unit of the Directorate of University Farms (DUFARMS), Federal University of Agriculture, Abeokuta, Ogun State. The experimental site is located in the derived savannah vegetation zone of South-western Nigeria. The location lies between latitude $7^{0} 10^{\circ} \mathrm{N}$ and $3^{0} 2^{0} \mathrm{E}$. (Google Earth. 2019).

\section{Experimental birds and management}

A total of three hundred and ninety-six (396) day old improved indigenous breeds (FUNNAB Alpha) were procured from FUNAAB hatchery and reared for two weeks in the brooding pen. During the brooding period, birds were fed ad libitum with the commercial diet. ICD was used as light source during this period and charcoal pots as source of heat. With a view to provide a warm environment for the chicks, the brooding pen was covered with black polythene and gradually uncovered towards the end of the brooding period. A digital hydrometer was suspended in the brooder pen to monitor the temperature and relative humidity. Throughout the experiment, the birds were raised on deep litter using wood shavings as litter material. Vaccination and medication programs were strictly adhered to.

\section{Experimental design}

During the $2^{\text {nd }}$ week of brooding, the birds were randomly divided into three treatments, each treatment contained a coloured CFL bulb of $45 \mathrm{~W}$ and equal light intensity: T1 (Yellow CFL), T2 (Blue CFL), T3 (White CFL) using a Completely Randomized Design. Each treatment held a hundred and thirty-two birds and they were further divided into 12 replicates each replicate contained 11 birds. Artificial lighting was provided for 8 hours from 8pm-4am. 


\section{Data collection}

\section{Predilection test: Dark to Light}

This experiment was carried out in three experimental units each comprising of four compartments (with wire mesh doors) arranged such that a single compartment is directly opposite the other three. Sixteen birds were selected from each treatment (tagged for easy identification) i.e. 48 birds were used in total and kept in the single compartment otherwise known as the dark pen for 2 hours of habituation, with no artificial light, feeder and drinker but with good litter. The three opposite compartments (with feeders, drinkers and good litters) were illuminated with one of the three light colours using CFL bulbs and separated with opaque polythene nylon and solid board to prevent light penetration. An eight unit Closed-circuit Television (CCTV) with infrared cameras embedded was installed in the pen for behavioural recording. After two hours, the door of the single compartment was opened, and the birds moved freely according to their Predilection for the light colours in the three opposite compartments. The behaviours of the birds under respective light colours were recorded for four consecutive hours. Behavioural recording was watched, the feeding and drinking behaviour of birds under each light were recorded once every
30 minutes.

\section{Growth performance}

Initial weights of birds were taken at the beginning of the experiment. Feed and water given, and feed and water leftover were recorded daily. Average feed intake, average water intake, average weight gain, and feed conversion ratio (FCR) were calculated.

\section{Statistical analysis}

Data collected was analysed using one-way Analysis of Variance (ANOVA) via General Linear Model (GLM) using MINITAB '17 and all means of significance were separated using Tukey's test.

\section{Results}

Dark-light predilection test of FUNNAB Alpha chicken at 2 weeks old

The behaviour of FUNAAB Alpha broilers under the preferred yellow light colour at 2 weeks old is shown in Table 1. Preferred yellow light colour had significant $(\mathrm{P}<$ 0.05 ) effect on feeding and drinking behaviour. FUNAAB Alpha broilers under yellow light had enhanced $(\mathrm{P}<0.05)$ frequency of feeding behaviour (3.6) compared to those under blue light (1.1) and white (0.7) light colours respectively. Moreover, birds that preferred yellow light exhibited higher frequency $(\mathrm{P}<0.05)$ of drinking behaviour (0.6) compared to those that preferred other lights colours.

Table 1: Dark- light predilection test of FUNNAB Alpha chickens at 2 weeks old

\begin{tabular}{llllll}
\hline Parameters & YELLOW & BLUE & WHITE & SEM & P value \\
\hline Feeding & $3.6^{\mathrm{a}}$ & $1.1^{\mathrm{b}}$ & $0.7^{\mathrm{b}}$ & 0.89 & 0.001 \\
Drinking & $0.6^{\mathrm{a}}$ & $0.0^{\mathrm{b}}$ & $0.0^{\mathrm{b}}$ & 0.19 & 0.010
\end{tabular}

$\overline{\mathrm{a}, \mathrm{b}}$ Different letters indicate significant differences between means within rows $(\mathrm{p}<0.05)$

SEM- Standard Error of Mean

Hourly average frequency of feeding and drinking behaviour of FUNNAB Alpha birds under Yellow, Blue and White at 2 weeks of age
The average feeding frequency of FUNAAB Alpha chicken under preferred light colours based on hours is shown in Figure 1. 
Predilection and growth performance of FUNAAB-Alpha chicken

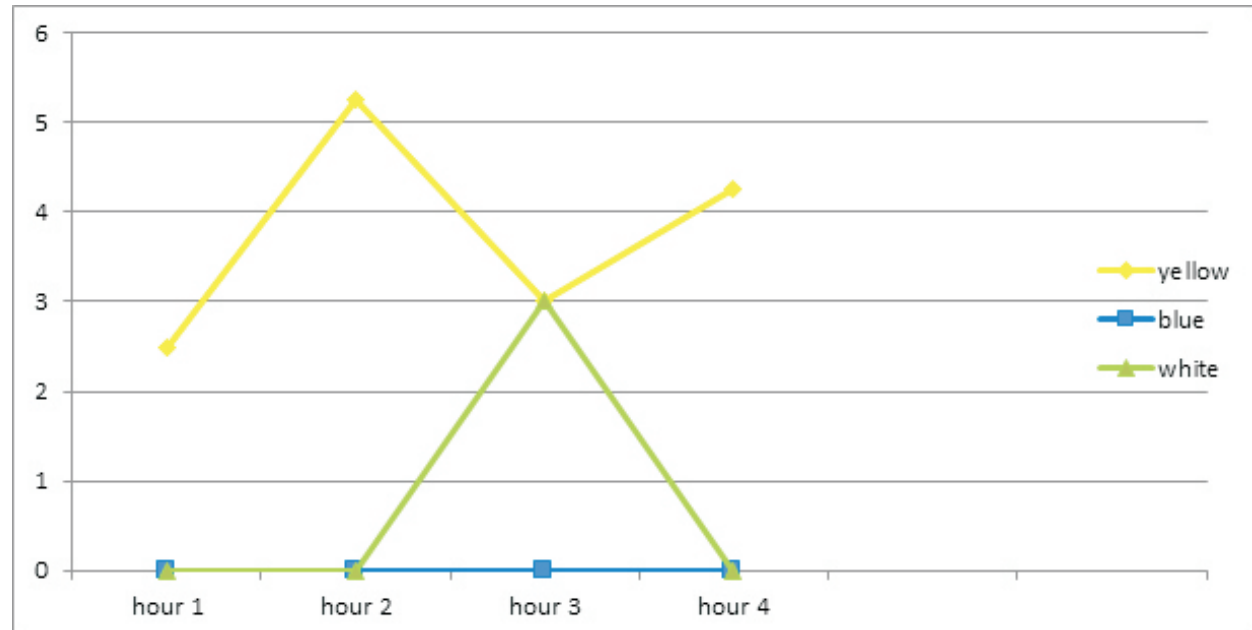

Figure 1: Hourly average frequency of feeding behaviour of FUNNAB Alpha birds under Yellow, Blue and White at 2 weeks of age

The highest feeding frequency was exhibited by birds that preferred yellow light. The average drinking frequency of
FUNAAB Alpha chicken under preferred light colours based on hours is shown in Figure 2. Drinking behaviour was exhibited only under yellow light colour.

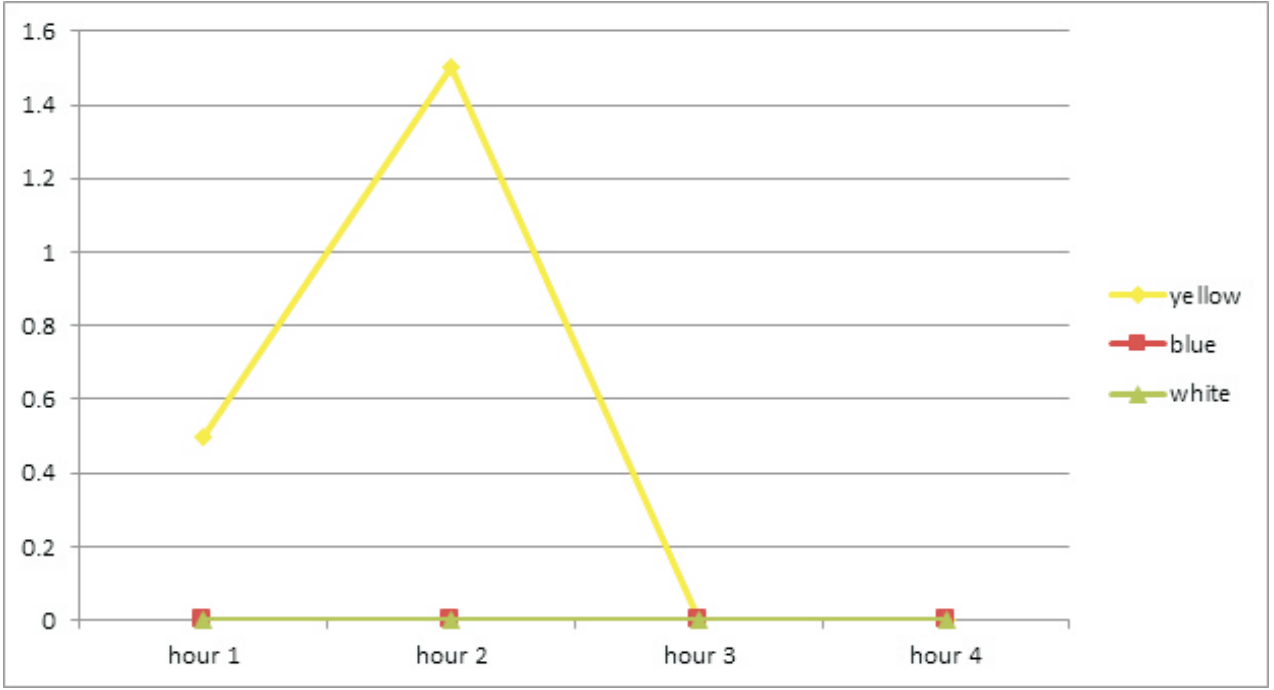

Figure 2: Hourly average frequency of drinking behaviour of FUNNAB Alpha birds under Yellow, Blue and White at 2 weeks of age

Growth performance of FUNAAB AIpha chicken at $2^{\text {nd }}$ weeks of age

The effect of light colours on growth performance of FUNNAB Alpha chicken at 2 weeks of age is shown in Table 2 . Light colours had significant $(\mathrm{p}<0.05)$ effect on average feed intake per bird. FUNAAB Alpha broilers reared under blue light colour had enhanced average feed intake (77.4) compared to birds reared under white (69.2) and yellow (70.0) light colours. 
Table 2: Growth performance of FUNAAB Alpha chickens at $2^{\text {nd }}$ week

\begin{tabular}{llllll}
\hline Parameter & Yellow & Blue & White & SEM & P Value \\
\hline Initial weight $(\mathrm{g} /$ bird $)$ & 170.5 & 168.1 & 170.6 & 2.50 & 0.913 \\
Final weight $(\mathrm{g} /$ bird $)$ & 699.8 & 672.4 & 666.2 & 33.58 & 0.494 \\
Average weight gain $(\mathrm{g})$ & 17.9 & 17.4 & 16.2 & 1.70 & 0.224 \\
Average feed intake $(\mathrm{g} / \mathrm{bird})$ & $69.6^{\mathrm{b}}$ & $77.4^{\mathrm{a}}$ & $70.0^{\mathrm{b}}$ & 8.22 & 0.001 \\
Average water intake(ml) & 105.9 & 105.5 & 104.4 & 1.55 & 0.886 \\
Average FCR & 2.7 & 2.8 & 3.0 & 0.31 & 0.496 \\
\hline
\end{tabular}

${ }^{\mathrm{a}, \mathrm{b}}$ Different letters indicate significant differences between means within rows $(\mathrm{p}<0.05)$

SEM- Standard Error of Mean

\section{Discussion}

These results showed that preferred light colours had influence on their feeding and drinking behaviour. Birds under yellow CFL bulb exhibited higher frequency of feeding and drinking behaviour compared to those that preferred blue and white CFL bulb colours. This could be attributed to the tetrachomatic vision of birds which enable them to distinguish the red and green colour spectrum dispersed under a yellow light. Prayitno et al. (1997) reported that red spectrum increases the frequency of feeding behaviour. Due to the red spectrum present in yellow light, FUNAAB Alpha broilers were more attracted to feeder and drinker under yellow light. It was also realized that yellow light colour has a stimulating effect on broiler birds (Jiang et al., 2012; Kim et $a l .$, 2012). The hourly mean graph (Fig. 1) revealed that FUNAAB Alpha broilers that visited the yellow light carried out more feeding behaviour than they did under any of the other light colours. FUNAAB Alpha broilers that visited the blue light exhibited feeding behaviour at the third hour while birds that visited the white colour failed to exhibit feeding behaviour. Reasons for this were unknown. Birds that preferred yellow light also exhibited the highest drinking behaviour at the second hour (Fig. 2). The exhibited behavioural frequency under yellow light could be attributed to the complementary nature of drinking and feeding behaviours Seneratna et al. (2012) noted that associated behaviours also depend on the time of the day under tropical environmental conditions. FUNAAB Alpha broilers that showed predilection for white and blue light colours exhibited no drinking behaviour during the predilection test. The cause of this was unknown. The result of this predilection test contradicted the findings of Angelica et al. (2013) who carried out a similar experiment using yellow and white LED bulbs. Angelica et al. (2013) opined that chickens did not show any behavioural sign of predilection for any of the light environments. The result of the growth performance (Table 2) indicated that birds reared under blue light colour had increased feed intake compared to those under yellow and white light colours, although the initial weight, final weight, average weight gain, average water intake and average feed conversion ratio remained unaffected. This is contrary to the findings of Son and Ravindran (2009) who carried out a similar experiment using broiler birds. They reported that blue (light had no effect on feed intake of broilers.

\section{Conclusion}

The study showed that FUNAAB Alpha broilers preferred yellow light colour to blue and white light colours and exhibited more feeding and drinking behaviours under the yellow light colour than blue and white light colours. The study also indicated that FUNAAB Alpha broilers under blue light colour had higher feed intake however, those under yellow light colour had better feed conversion ratio. Yellow light colour is therefore, 
recommended for rearing of FUNAAB Alpha broilers at the early stage.

\section{References}

Angélica, S. M., Sandro J. P., Rasiel R., Gabriela, M. M., Daniella, J. M. and Jean C. P. 2013. Performance and preference of broiler chickens exposed to different lighting sources. Journal of Applied Poultry Research 22:62-70.

Adeleye, O. O., Egbeyale, L. T., Ayoajasa, O., Abatan, M. O., Abudkareem, A. W., Odukoya, A. O. and Akinsola, O. E. 2018. Growth performance of broiler chicken reared under two different light bulb source and distance. Abstracts, British Poultry Abstracts, 14:1, 1-35.

Davis, N. J., Prescott, M. B., Savory, C. J. and Wathes, C. M. 1999. Preference of growing fowls for different light intensities in relation to age, strain and behaviour. Animal Welfare 8:193-203.

Kim, M. J., Hossain, M. S., Nazma, A., Jae, C. N., Han, B. T., Hwan, K. K., Dong, W. K., Hyun, S. C., Hee, C. C. and Ok, S. S. 2012. Effect of monochromatic light on sexual maturity, production performance and egg quality of laying hens. Avian Biology Research 5:69-74.
Olanrewaju, H. A., Thaxton, J. P., Dozier, W. A., Purswell, J., Roush, W. B. and Branton, S. L. 2006. A review of lightning programs for broiler production. International journal of poultry Science 5: 301-308.

Prescott, N. B. and Wathes C. M. 1999. Spectral sensitivity of the domestic fowl (Gallus gallus domesticus). British Poultry science 40:332339.

Prayitno, D. S., Philips, C. J. and Omed, H. 1997. The effect of colour and lightning on the behaviour and production of meat chickens. Poultry Science, 76: 452-457.

Rozenboim, I., Biran, I., Chaiseha, Y., Yahav, S., Rosenstrauch, A., Sklan, D. and Halevy O. 2004. The effect of green and blue monochromatic light combination on broiler growth and development. Poultry Science 83: 842-845.

Vandenberg, C. and Widowski, T. M. 2000. Hen's preferences for highintensity high pressure sodium or low-intensity incandescent lighting. Journal Applied Poultry Science 9:172-178.

Received: 6 $^{\text {th }}$ April, 2019

Accepted: $27^{\text {th }}$ July, 2019 